\title{
Research of Permanent Magnetic Brushless DC Motor Fuzzy Self-adaptive PID Controller Based on Matlab / Simulink
}

\author{
Wang Xuejie, Wang Peng† \\ School of Information \& Electrical Engineering \\ Zhejiang University City College \\ Hangzhou, China \\ xjwang@zucc.edu.cn; wp-lx@163.com
}

\author{
Lou Ying \\ School of Electrical \& information \\ Liaoning Science and Technology University \\ Anshan, China \\ louying70@126.com
}

\begin{abstract}
The permanent magnet brushless DC (BLDC) motor is a typical Multiple variables, nonlinear system. In this paper, the fuzzy control technique was applied to the BLDC control system, realization of traditional PID controller parameters on line adjustment, the BLDC double closed loop speed regulation system modeling and fuzzy controller for the traditional PID controller optimization effect has been completed by using the power electronic simulation database and fuzzy control toolbox. The simulation results show that: the dynamic performance of the system is improved and the system overshoot diminished at the same time by comparing the Fuzzy PID controller with the traditional PID controller.
\end{abstract}

Keywords- BLDC; Simulink; Fuzzy PID controller; adaptive

\section{INTRODUCTION}

Brushless DC motor control system is a typical nonlinear, multivariable coupling system, the traditional PID control algorithm is simple and easy to implement, but not easy to meet the requirement of high precision servo control system and it is difficult to achieve high precision operation of motor[1]. Nonlinear control method has been fully applied in Brushless DC motor control and it lays the foundation for realizing controlled system high quality dynamic capability and stability based on modern control theory and intelligent control theory. In this paper, fuzzy control technology is combining with traditional PID control technology to implement fuzzy adaptive PID control strategy, and the graphic simulation model is built on the Matlab / Simulink platform[2]. Fuzzy adaptive PID controller of computer simulation is studied by means of Simulink simulator and fuzzy toolbox. It can adequately explain the traditional PID controller with fuzzy control theory can obtain obvious the effect better than that of the single controller, and it has practical significance of the fuzzy adaptive PID controller application[3].

\section{BRUSHLESS DC MOTOR DIFFERENTIAL EQUATION MODEL}

In this paper, the motor selects poles three-phase brushless DC motor, stator winding is the centralized moment winding $\mathrm{Y}$ connection, the rotor adopts implicit pole rotor structure.

An arbitrary winding phase voltage can be expressed as:

$$
u_{A}=R i_{A}+\frac{d}{d t}\left(L_{A} i_{A}+M_{A B} i_{B}+M_{A C} i_{C}\right)+e_{A}
$$

Where $e_{A}$ is the EMF of phase $A, M_{A B}, M_{A C}$ is the Mutual inductance of $\mathrm{B}$ phase winding and $\mathrm{C}$ phase winding to A phase winding respectively. Brushless DC motor rotor ordinary can be considered the winding inductance is not changing with time constants by using surface sticking type pole structure[4]. Because the three-phase winding structure symmetry, each winding self inductance is equal, mutual inductance between phase windings are equal too, that is $\mathrm{L}_{\mathrm{A}}=\mathrm{L}_{\mathrm{B}}=\mathrm{L}_{\mathrm{C}}=\mathrm{L}, \mathrm{M}_{\mathrm{AB}}=\mathrm{M}_{\mathrm{BA}}=\mathrm{M}_{\mathrm{BC}}=\mathrm{M}_{\mathrm{CB}}=\mathrm{M}_{\mathrm{AC}}=\mathrm{M}_{\mathrm{CA}}=\mathrm{M}$.

Because three-phase currents meet $i_{A}+i_{B}+i_{C}=0$, (1) can be further simplified to:

$$
u_{A}=R i_{A}+(L-M) \frac{d i_{A}}{d t}+e_{A}
$$

We can get the brushless DC motor phase voltage equation matrix expression:

$\left[\begin{array}{l}u_{A} \\ u_{B} \\ u_{C}\end{array}\right]=\left[\begin{array}{lll}R & 0 & 0 \\ 0 & R & 0 \\ 0 & 0 & R\end{array}\right]\left[\begin{array}{l}i_{A} \\ i_{B} \\ i_{C}\end{array}\right]+\left[\begin{array}{ccc}L-M & 0 & 0 \\ 0 & L-M & 0 \\ 0 & 0 & L-M\end{array}\right] \frac{d}{d t}\left[\begin{array}{l}i_{A} \\ i_{B} \\ i_{C}\end{array}\right]+\left[\begin{array}{l}e_{A} \\ e_{B} \\ e_{C}\end{array}\right]$

Similar with the DC motor, the motor absorptions the power from the power supply when the motor operation, a small part of the power can be changed into the copper loss and iron loss, most of the power of the permanent magnets of the rotor torque is transmitted to the rotor through the air-gap magnetic field, this part of the power is electromagnetic power, it is equal to the three phases EMF and current product sum, i.e:

$$
P_{e}=e_{A} i_{A}+e_{B} i_{B}+e_{C} i_{C}
$$

In spite of the rotor mechanical loss and stray loss, electromagnetic power is completely converted into kinetic energy of the rotor, so

$$
P_{e}=T_{e} \cdot \Omega
$$

Where $T_{e}$ is the electromagnetic power, $\Omega$ is the Mechanical angular velocity. So

$$
T_{e}=\frac{e_{A} i_{A}+e_{B} i_{B}+e_{C} i_{C}}{\Omega}
$$


The motor motion equation is :

$$
T_{e}-T_{L}=J \frac{d \Omega}{d t}+B_{v} \Omega
$$

Where $\mathrm{T}_{\mathrm{L}}$ is Load torque, $\mathrm{J}$ is Rotor moment of inertia, $\mathrm{B}_{\mathrm{V}}$ is the Viscosity coefficient.

\section{BRUSHLESS DC MOTOR CONTROL SYSTEM BLOCK DIAGRAM}

In various control strategies applied to brushless DC motor controller, double closed-loop PI technology is the most mature and is widely applied. The outer loop is velocity loop (voltage loop) in Double closed-loop control, its main effect is to maintain steady speed and resist load disturbance[5]. The inner loop is current loop (torque loop), mainly to stable current and resistance to voltage effect. The design of brushless DC control system speed controller needs to consider work environment, load characteristic, position detection issues such as ways, the goal is to achieve a speed control system with wide speed range, small static error, good following and anti jamming performance. Traditional PID controller has the advantages of simple structure and easy to implement, but not easy to meet the requirement of high precision servo control system and it is difficult to achieve high precision operation of motor. This paper put forward optimization fuzzy controller based on the traditional PID. Using fuzzy rules to optimize traditional PID controller parameters to achieve the optimal operation, as shown in figure 1.

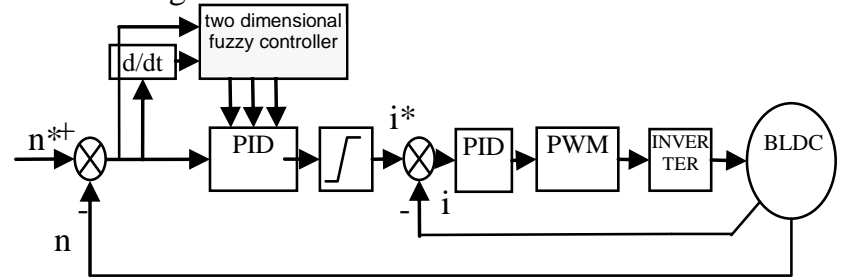

Figure1. Double closed- loop speed regulation system with optimization fuzzy controller

The Simulink environment provided by MATLAB is a ideal tool of solution a nonlinear system modeling, analysis and Simulation. In addition to the more commonly used simulation module, the Simulink also provides module library in the toolbox forms for different research areas, including power electronic simulation database and fuzzy toolbox. This paper mainly uses power electronic simulation library ( SimPowerSystem ) and fuzzy toolbox ( Fuzzy Logic Toolbox )to establish brushless DC motor control system based on figure 1.

Brushless DC motor double closed loop speed control system block diagram is shown in figure 2 .

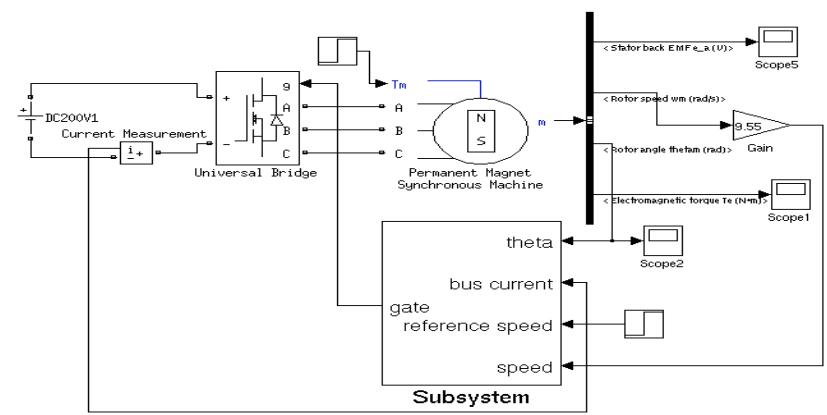

Figure2. Brushless DC motor double closed loop speed control system block diagram

The whole system in figure 2 consists of 4 parts:

A. power supply module

The ideal voltage source, voltage is set to $200 \mathrm{~V}$.

\section{B. Motor}

Select "Permanent Magnet Synchronous Machine" module; selection of magnetic flux density distribution of breath trapezoidal" Trapezoidal Model Electrical System", flat top width of 120 electrical degrees.

\section{C. measurement unit}

The unit mainly consists of a data bus structure to measure the voltage, current, speed ,angle and other variables when the motor operating, observation through the oscilloscope display.

\section{D. controller unit}

Double closed-loop speed regulation function is implemented by dual closed loop controller subsystem known as " Subsystem", the input variables are corner, bus current, reference speed and measuring speed, six PWM pulse is output to the inverter bridge ( Universal Bridge ), PWM signal frequency is $20 \mathrm{khz}$.

\section{SIMULATION RESULTS}

Given a reference speed of $1000 \mathrm{rpm}$, the load torque is $1 \mathrm{~N} \cdot \mathrm{M}$. Figures 3 to 5 are the control waveform under PID, Figure 6 to figure 8 are control waveform under the fuzzy adaptive PID.

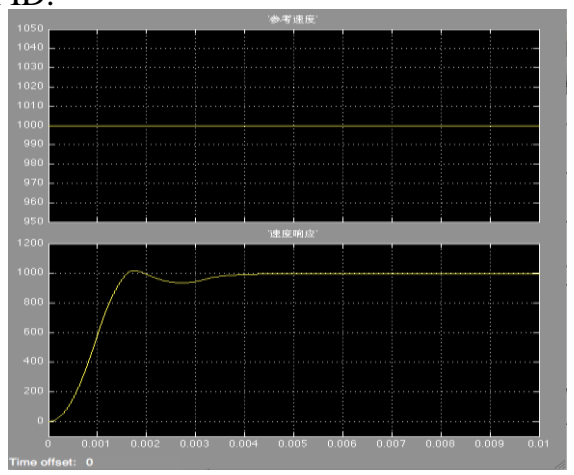

Figure 3.speed response curve under PID 


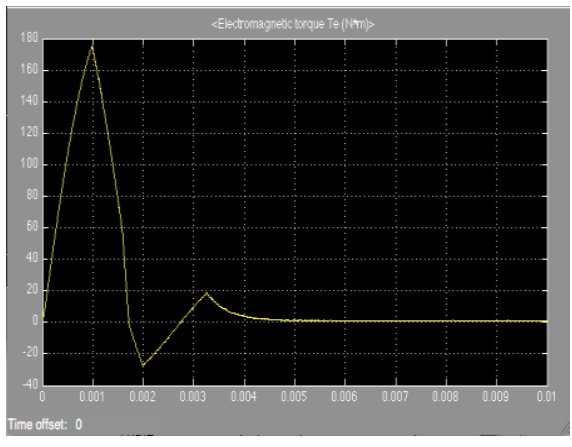

Figure 4. torque response curve under PID

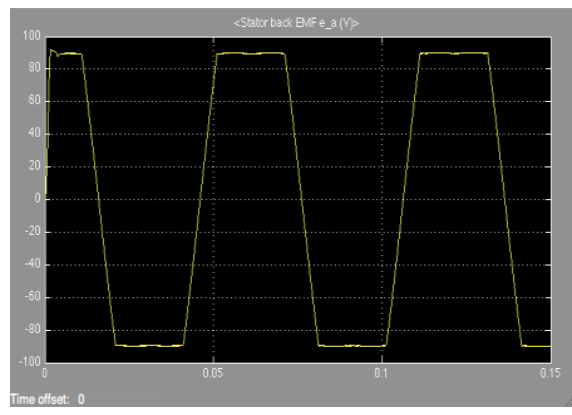

Figure 5. A-phase back EMF curve under PID

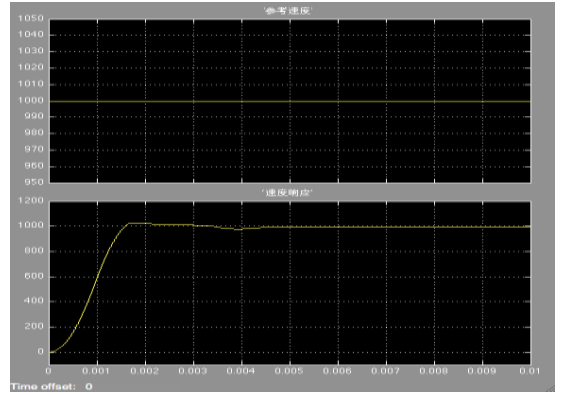

Figure 6.speed response curve under fuzzy adaptive PID

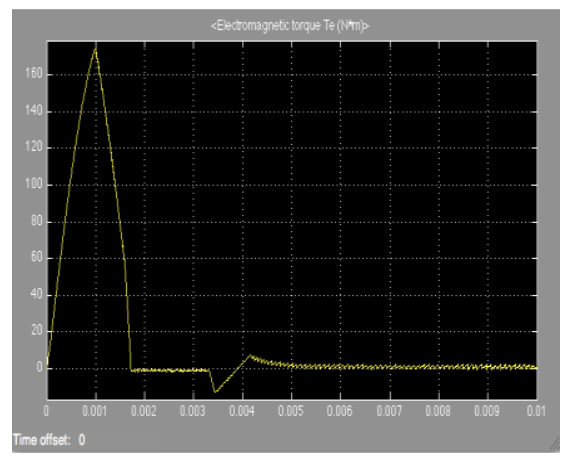

Figure 7. torque response curve under fuzzy adaptive PID

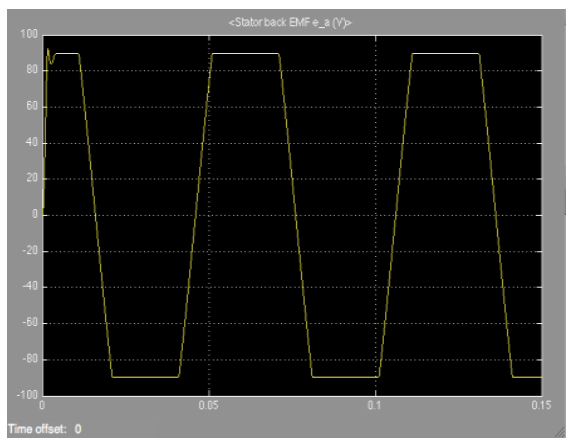

Figure 8. A-phase back EMF curve under fuzzy adaptive PID

\section{CONCLUSION}

The paper proposed one speed control system of fuzzy self-adaptive PID control of brushless DC motor based on the mathematical model of BLDCM. In the Simulink environment, it realize the simulation of double closed loop system of current and speed fuzzy adaptive PID control. These simulation results and analysis show that waveform is consistent with the theoretical analysis, system to speed up response time, this system has advantage of fast response time, high regulation accuracy, disturbance attenuation and static performance, almost no overshoot and oscillation, besides it has strong adaptability and robustness, it has great significance for the actual process control. The model can easily modify and replace function module.

\section{ACKNOWLEDGMENT}

This work is supported by the construct program of the Key Laboratory of Intelligent System in ZUCC; Zhejiang Province Higher Education Teaching Reform Project "Based on Modeling and Solution Model Theory of Motor Application Technology Project Driven Classroom Teaching Reform"(kg2013510); Zhejiang University City College excellent course "Electrical Application Technology" (JP1104); Zhejiang Province Soft Science Project "The Research of Synergistic Innovation Strategic of Emerging Industries in Zhejiang Province"(2013C35062).

†Corresponding author.

\section{REFERENCES}

[1] H. Shi. The BLDC motor fuzzy control based on DSP [D]. Master's thesis, Zhejiang University, 2006.

[2] Z.Q.Zhu and Howed. Electrical machines and drives for electric, hybrid, and fuel cell vehicles[J]. Proceeding of the IEEE, vol. 95, Apr. 2007, pp. 746-765.

[3] Awadallahma and Morcosmm. Automatic diagnosis and location of open-switch fault in brushless dc motor drives using wavelets and neuro-fuzzy systems[J]. IEEE Transaction on Energy Conversion, vol 21, Jan. 2001, pp.104-111.

[4] Guptara, Kumarr and Bansalak. Artificial intelligence applications in Permanent Magnet Brushless DC motor drives[J]. Artificial Intelligence Review, vol 33, Mar. 2010, pp.175-186.

[5] P. Xiang and X. Liang. ModeI and system simulation of the BLDCM based on fuzzy controler[J]. Industrial instrumentation and automation, 2011, 1: 39-42. 